\title{
It Takes a Couple to Tango: Antecedents to Collaborative Decision-Making
}

\author{
Olena Koval *(D) and Håvard Hansen
}

Norwegian School of Hotel Management, University of Stavanger, N-4036 Stavanger, Norway; hh@emeriti.no

* Correspondence: Olena.koval@uis.no

\begin{abstract}
Existing research on vacation-related choices in couples concentrates on variables related to roles and influence in attempt to explain decision-making processes. However, as experienced from 2019-2021 COVID pandemic, travel-related decisions in couples may be characterized by higher complexity and risks, both in relation to health and economy. As the consequences of such decisions may affect both partners, the couples might benefit from a collaborative approach. This study investigates how certain known facilitators of group collaboration are associated with romantic couples' perception of collaboration in the context of vacation choices. The data were collected by means of a cross sectional design, and 112 individuals from Norway who were in romantic relationships completed the survey. Multi-item scales were used and validated with factor analysis; the hypotheses were tested using multiple regression. Four of the five hypotheses were empirically supported, and shared experiences, flexibility, engagement, and partners' support positively affected the perception of collaborative decision-making. No effect was found for role exchange. The results of this study may help to gain a better understanding of how couples make decisions together, and how firms can adapt their communication and service design to increase their appeal to this large tourism segment.
\end{abstract}

Citation: Koval, Olena, and Håvard Hansen. 2021. It Takes a Couple to Tango: Antecedents to Collaborative Decision-Making. Social Sciences 10: 245. https://doi.org/10.3390/ socsci10070245

Academic Editors: Steven B. Sheldon and Nigel Parton

Received: 13 April 2021

Accepted: 23 June 2021

Published: 26 June 2021

Publisher's Note: MDPI stays neutral with regard to jurisdictional claims in published maps and institutional affiliations.

Keywords: collaboration; couples; decision-making; travel; decision satisfaction; flexibility; engagement; role exchange; shared experiences; partner's support

\section{Introduction}

With the global tourism industry being seriously affected by 2020-2021 COVID-19 pandemic, consumer groups, and mainly couples, have been facing challenges related to booking uncertainty and cancellations of costly vacation purchases due to border closure, lock-downs, and various governmental and local restrictions (Gössling et al. 2020; UNWTO 2021; Abdullah et al. 2020). According to a survey conducted in March 2020 involving 1509 respondents from the UK alone, 27 percent reported that they had to delay booking their vacations, 11 percent felt being forced to cancel already booked vacations, and 8 percent voluntarily cancelled their booked trips (Statista 2021). Such unforeseen circumstances have undoubtedly challenged consumers' decision-making skills. A simple search on Google like "COVID-19 family vacations" has given us numbers of pages with discussions of challenges related to making vacation choices during COVID-19. Because in the first place many vacation choices in couples are complex decisions as they are oftentimes characterized by high cost and require pre-planning, it would be beneficial for couples to have an efficient decision-making process (Kroesen and Handy 2014).

The idea of understanding how couples make vacation-related decisions is not new to the areas of tourism and consumer behavior research and encompasses over 40 years of scientific investigation (Filiatrault and Ritchie 1980). Most of the existing literature on purchase decision-making in couples is built on resource theory, sex-role orientation, least-interested partner hypothesis, and involvement (Webster and Reiss 2001). Specifically, most of the research available in the area focuses on the traditional family and mainly 
on the variables related to power, influence, and gender/marital roles explored in an attempt to identify which of the partners makes the final decision (Razzouk et al. 2007; Rojas-de-Gracia et al. 2019; Simpson et al. 2012). However, the social and demographic changes (more women at work and an increased number of dual-earner couples) seen during the last decades made it clear that "you or me" approach to understanding how couples make decisions is not sufficient enough (Bronner and De Hoog 2008; Webster and Reiss 2001).

Indeed, such an approach may be satisfactory and time saving for routinized choices made under somewhat repeating scenarios, like buying groceries or renting a car at a destination. However, bigger and more complex decisions couples make do not take place in a vacuum and are oftentimes shaped by their social environment (Garbinsky and Gladstone 2019; Queen et al. 2015). Consequently, tourism couples may face new challenges that may require expertise beyond that of one of the partners. "Linear approach" which has been applicable for several decades ago may not solve the complexity challenges we are facing now. Working not against the changes but together with them may bring new insights to the area of decision-making in couples.

This study suggests that under more complex circumstances, couples who make travelrelated choices would benefit from a collaborative approach, utilizing their interpersonal resources. Existing research demonstrates that complex decisions made in couples, such as medical (Hilton et al. 2000) and retirement choices (Moen et al. 2006), benefit from interpersonal collaboration (Anderson et al. 1998; Witteman 1988). Yet, existing research on collaborative decision-making in consumer couples is in its early stage and only touches the surface of the potential for our understanding of the phenomenon (Queen et al. 2015). The lack of such an approach is quite surprising, considering the fact that decisions made by members of other primary and secondary groups are found to be characterized by higher quality and greater acceptance by those who are affected by them (Harrison 1999), and by the positive impact of collaboration on decision satisfaction (Witteman 1988).

Still, as simple as it may sound, for effective collaboration to take place, it is critical to know what influences and constitutes collaboration, as well as having a clearer understanding of what collaboration in tourism couples looks like (Bronstein 2003). Therefore, the aim of this study is to give an insight into how certain known antecedents of collaboration may shape perceived collaboration among Norwegian individuals in close relationships and in the context of vacation-related choices. Addressing the lack of research on collaboration in consumer and tourism research (Queen et al. 2015), and building on the knowledge on interpersonal collaboration in groups, we suggest the conceptual model where flexibility, shared experiences, role exchange, partner's support, and engagement affect the perception of decision-making collaboration among romantic partners. An overview of each of the factors is provided below, along with theoretical framework and relevant research. For this study we define couples as two married or unmarried individuals operating as a group, who have strong interpersonal relationships, which should be taken into consideration if we want to understand them (Couto et al. 2018; Razzouk et al. 2007; Webster and Reiss 2001). Our definition of a couple reflects the values settled in up to date society and it is rather different from its traditional conceptualization as a husband and a wife in earlier consumer and tourism research (Filiatrault and Ritchie 1980).

In the next chapter we present the theoretical framework and our five research hypotheses, followed by a material and methods section, in which we present the design of the study, its sample, and measurement instruments. We then present results and discussion chapters, followed by limitations, suggestions for future research and conclusions.

\section{Theoretical Framework and Research Hypotheses}

Collaborative problem solving takes place when two or more individuals work together to perform a task (Berg et al. 2011), approaching the problem at hand as shared, rather than owned by one of the partners (Berg et al. 2020). Depending on the environment where the term collaboration is used, and the number of participants involved, it has a 
variety of meanings and is frequently used in the literature interchangeably with other terms such as "shared decision-making" and "joint decision-making" (Hara et al. 2003). For this study, collaborative decision-making in tourism couples is defined as an interpersonal process where two partners interact by means of negotiation and compromise to make a choice or to come to an agreement (Bronstein 2003).

Our conceptual model of collaboration in couples was developed somewhat inspired by Bronstein (2003). This means that we used the multidisciplinary theory such as the theory of joint/shared decision-making in couples, mainly related to medical and retirement decisions, and the theory on collaboration in emergency management (Kapucu and Garayev 2011; Koval and Hansen 2019; Mattessich and Monsey 1992; Politi and Street 2011). We identified factors of collaboration that consistently appeared in the literature, focusing on those related to interpersonal processes rather than individual characteristics of the partners.

One may argue that the factors that affect collaboration in close relationships may differ from those in less intimate groups. For instance, it may be questioned whether the facilitators of collaboration in the context of workplace or scientific collaboration may be applicable to couples. With regard to this we refer to Hara et al. (2003), where a number of informants compared collaboration to a marriage, since factors like trust, friendship, good communication, and mutual efforts to make things work were identified as extremely important for a fruitful collaboration. Moreover, Kanter (1994) in her research of business alliances, indicated that her informants used romances as an analogy for collaboration. Interestingly, if parallels between romances and collaboration may be drawn, as indicated by previous research, the factors that would be crucial for decision-making collaboration in close relationships should resemble factors that influence the success of romantic relationship. In their turn, Queen et al. (2015) have emphasized the importance of understanding how, for instance, interpersonal resources influence how couples collaborate to make consumer and financial decisions. In this study, a conceptual model is presented that depicts five key factors which, as we suggest, facilitate vacation-related collaboration in couples. These factors and their corresponding hypothesis are outlined in the subsequent paragraphs, before summarized into a conceptual model.

\subsection{Shared Experiences}

The first variable expected to influence the degree of collaboration among tourism couples is shared experiences. We define shared experiences as joint activities which have resulted in specific knowledge that is applicable to future decisions (Oh et al. 2007). As first described by Dewey (1938) and further discussed by Nan Restine (1997), learning from experience implies making sense of experiences, connecting them with past experiences, and integrating what is learned into one's actions.

The literature on collaboration describes knowledge from the choice relevant area as one of the most important factors influencing successful collaboration (Mattessich and Monsey 1992). For instance, Kanter (1994) listed three main criteria that are often employed when companies look for alliances: self-analysis, chemistry, and compatibility. It is compatibility that in Kanter's term includes "compatibility on broad historical, philosophical, and strategic grounds: common experiences, values and principles, and hopes for the future" (Kanter 1994, p. 101). It would imply that they had complementary approaches to business. This can go parallel with our view of successful collaboration in close relationships. When partners have a history of solving decision problems together, they develop a shared kind of tacit knowledge that is applicable to future situations. They learn how to best arrive at solutions, how to go ahead in the process in a way that accommodates the needs of both partners, and they learn the preferences and expectations of each other. This is argued to be fruitful for future collaborative efforts.

Furthermore, existing research on collaborative decision-making in emergency management and clinical encounters highlighted the importance of contributing knowledge and information to collaborative decision-making, and negative consequences from failing 
to do so (Kapucu and Garayev 2011; Politi and Street 2011). After combining knowledge and experience from each other, parts involved into a decision situation are expected to have a shared understanding of the issue at hand and can thus constructively contribute to problem solving in a collaborative manner (Kapucu and Garayev 2011). We argue that this may also be applicable to vacation-related contexts. Couples who have developed the knowledge relevant for collaboration, will apply this knowledge also when a complex decision at hand concerns vacations or leisure travels. Thus, there is a reason to believe that shared decision experiences will create a collaborative environment, by means of knowledge-based discussions, and the contribution of both partners to the choice situation. Given this discussion, it is suggested that:

Hypothesis 1 (H1). There is a positive relationship between the perception of shared experiences and the perception of decision-making collaboration.

\subsection{Behavioral Flexibility}

The next variable expected to influence the level of collaborative decision-making in close relationships is behavioral flexibility. Behavioral flexibility is a driver of successful collaboration, and a well-established concept in the area of health, education, public affairs arenas, and social science (Kapucu and Garayev 2011; Mattessich and Monsey 1992; Richey et al. 2012), as well as decision-making in general (Sharfman and Dean 1997).

Behavioral flexibility refers to acknowledging that different alternatives and options are available in almost all decision situations (Martin and Rubin 1995). Due to the specifics of the decision-making context in this study, a definition of behavioral flexibility which emphasizes its interpersonal aspects was chosen. Based on Zaccaro et al. (1991), Hall et al. (1998), and Martin and Rubin (1995), behavioral flexibility was conceptualized as the willingness of partners to adjust to each other's needs and preferences in a choice situation, and the awareness that any decision situation has several alternatives available. Behavioral flexibility in close relationships may be particularly important when partners face complex or previously unexperienced choice situations, such as moving to another place, making choices to adjust to new phase in the family life cycle, or making expensive purchases like a $€ 20,000$ cruise.

There is a body of literature suggesting that failure to be flexible in making strategic choices can have severe consequences for organizations (Sharfman and Dean 1997). In particular, the literature on collaboration describes flexibility as one of the main factors influencing the success of collaboration. In larger groups, this is usually achieved when collaborative groups are open to different ways of accomplishing its work, and to varied ways of organizing itself (Mattessich and Monsey 1992). Similarly, in the context of close relationships, the positive effect of flexibility on collaboration would be achieved when both partners are willing to try different ways of approaching a decision. The literature also suggests that the impact of flexibility on collaboration among partners may work through the principle of reciprocity (Richey et al. 2012). According to Gouldner (1960), the norm of reciprocity evokes obligation towards others based on the positive/negative behavior shown from them in the past. Thus, when one partner is open to adopt, the other partner is more likely to respond in a similar way when the opportunity arises. Consequently, in the long run, the positive effect of flexibility on collaboration during decision-making would be experienced by each partner. Concludingly, we suggest that:

Hypothesis 2 (H2). For tourism couples, perceptions of partner flexibility during choice situations are positively related to the degree of perceived collaboration.

\subsection{Engagement}

Engagement of partners in decision-making is important for the development of collaboration amongst them, as well as for their continued functioning as a team. Previous research on group decision-making has shown that for groups to perform effectively, the 
members must feel enthusiastic about the goals of the group, rather than being competitive (Harrison 1999). Thus, when both partners maximize their involvement in the vacation decision-making situation, they will work more cooperatively to ensure that their goals are met (Korsgaard et al. 1995). For example, empirical support for a positive effect of engagement on task performance has been well documented (Christian et al. 2011). Engagement can be conceptualized either as a psychological state, performance construct expressed by through behavior, or a mixture of them (Macey and Schneider 2008). In this study, engagement is seen as a psychological state expressed through commitment and enthusiasm. During complex vacation decisions couples make, stated or expressed engagement would further result in behavioral engagement, as described by Macey and Schneider (2008). Drawing on self-determination theory (Deci and Ryan 2000), we suggest that couples who are psychologically engaged in a vacation-related choice situation are more willing and open to negotiate and compromise with each other. Thus, engagement may not only benefit the process of collaboration in a positive way, but may also improve physical and psychological wellbeing of those involved (Meyer and Gagne 2008). It is therefore hypothesized that:

Hypothesis 3 (H3). There is a positive relationship between partners' engagement and the perception of decision-making collaboration.

\subsection{Role Exchange}

It is also argued that role exchange has a positive effect on the level of collaboration found for decision-making in tourism couples. Role exchange is defined here as a decisionrelated interaction of both partners, who contribute to the choice situation by exchanging roles/taking responsibility for different stages of a decision-making process. Participation of both partners at different stages of vacation decision situations is central to arrive at a unified solution (Rojas-de-Gracia et al. 2018). This participation, however, can differ from situation to situation, depending on the decision context at hand and who among the partners is better "equipped" to play the different roles across these different contexts. For example, the one who can best acquire information on alternative options for their pension savings may not be the partner most knowledgeable when it comes to the choice of honeymoon destinations, the 50th anniversary round-the-globe holiday, or family vacation.

Roles are generally acknowledged as a key factor that influences the success of collaborative decision-making. In organizational settings, for example, collaboration is achieved when groups clearly understand their roles and responsibilities and have a clear idea of how to carry those responsibilities (Mattessich and Monsey 1992). Moreover, by reducing role conflicts, a role exchanging approach allows for more fruitful collaboration among and within groups. Finally, existing research on collaborative decision-making has found the exchange component to be a core element of collaborative processes (Kapucu and Garayev 2011; Politi and Street 2011).

As consumer groups, such as couples, may be characterized by less defined and somewhat vague roles (Lobel 1991), there is reason to believe that couples approach decision-making situations in a more collaborative way. This point is strengthened by the fact that for couples to function effectively in complex decision-making situations, both partners need to be open to changing their roles depending on the choice situation. Such exchange would imply shifting between being, for instance, the initiator, user, decider, or the buyer. This is rather similar to the concept of a buying center within organizational decision-making (Kotler and Keller 2011). In summary, it is hypothesized that:

Hypothesis 4 (H4). For vacation-related decision making in couples, perceived role exchange between the partners has a positive relationship to the perception of decision-making collaboration. 


\subsection{Partner's Support}

The literature on behavior in smaller groups describes how collaborative decisionmaking is oftentimes much more than a cognitive process (Politi and Street 2011), and may be affected by elements like compatibility and internal incentives, such as personal motivation (Hara et al. 2003). The importance of internal incentives is highly emphasized, as external incentives alone seldom lead people to establish collaborations. By creating cooperative environments and "removing" barriers, these factors facilitate collaboration. Drawing on this, we believe that in the context of more intimate groups, such as couples, equivalent factors would play a role in the perception of collaboration in decision-making situations. Previous research has shown that highly satisfied couples' interactions are characterized by higher level of support (Fincham 2003), and we define partner's support as consisting of an emotional investment component and a behavioral component expressed by the amount of time partners are willing to invest in making decisions together. Being present both emotionally and in terms of time and place, increases the chances of both partners to develop favorable environments for collaboration (Hara et al. 2003). Consequently, the final hypothesis states that:

Hypothesis $\mathbf{5}$ (H5). There is a positive relationship between perceived partner support and the perception of collaboration.

\subsection{Collaboration and Decision Process Satisfaction}

An important aspect of any kind of collaboration is the end product (Kapucu and Garayev 2011). Research on participatory decision-making in primary and secondary groups has demonstrated positive outcomes of collaborative processes (Witteman 1988). For example, one study on medical collaboration demonstrated that, in terms of satisfaction, the best outcomes were for patients who were willing to collaborate with their physicians (Anderson and Gerbing 1988). Research on dyads has found that dyadic interaction can significantly enhance the quality of reasoning (Kuhn et al. 1997). Furthermore, research reveals that older couples may profit from collaboration in a highly demanding problemsolving tasks (Peter-Wight and Martin 2010). For vacation-related decisions in couples, such findings may imply a more effective approach to choice situations and an increased satisfaction with the final decision. To scrutinize how the variables in the model are related to central variables in an extended nomological network, we will teste whether the dependent variable was related to satisfaction with the decision processes. The theoretical model is portrayed in Figure 1. The methods employed to test the five hypotheses are presented in the next section.

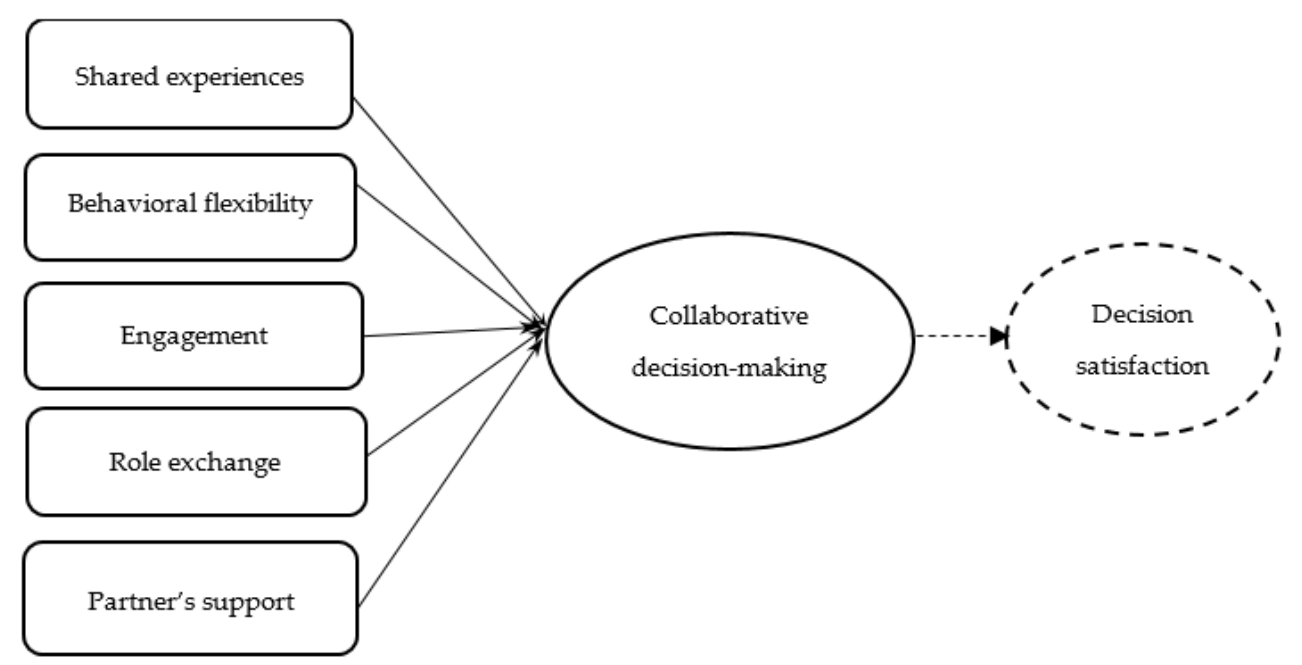

Figure 1. Suggested conceptual model of collaborative decision-making in couple. 


\section{Materials and Methods}

\subsection{Design and Sample}

The model presented concerns partners in close relationship and how they make decisions as a couple. It was therefore important to acquire the data that both enable a test of co-variations between the variables and stem from respondents in romantic relationships. The first was acquired by a cross sectional design with the data collected by means of a pen and paper-based survey where self-reported perceptions and experiences were measured for all latent variables. To ensure the data were in line with the focus of the study, some inclusion criteria were designed. Only respondents who have been in close relationships for at least one year and had experience in making complex decisions together were recruited. To get a sample of respondents in line with this, different organizations where members did pro bono work to raise funds for the organization (e.g., sports club for boys/girls) were approached. The contact person in these organizations, based on the sampling criteria, invited respondents from the parents and grandparents of the children in the club to participate. Those willing to participate put themselves on the list of participants, from which we randomly chose whom to include. The contact person informed everyone that participation in the study would raise approximately $\$ 20$ to the club. Hence, the incentive for participating was that the university would pay the organization of which they were members. The study participants were recruited to participate in the study conducted by the department of tourism and hospitality. The data collection took place during January-March 2019. The final sample consisted of 112 (50 percent male and 50 percent female) respondents from Norway, originating from different geographical areas in the region. The age span was from 24 to 71 , with an average of 45.8 years, while relationship length of our study participants ranged between 2 and 51 years, with an average of 21 .

\subsection{Instruments}

All variables were measured with multi-item scales, designed as five-point Likert type statements, from totally agree (5) to totally disagree (1). Shared experiences were measured using five items adapted from Oh et al. (2007), while the five measures for behavioral flexibility were adopted and modified from the cognitive flexibility scale (Martin and Rubin 1995). Six engagement items were modified from the consumer brand engagement scale (Solem 2015). To capture partner's support, one item from Greenberger and Goldberg (1989) was adopted, focusing on time a partner invested in joint decision-making, and three items measuring emotional support were modified from Saavedra and Van Dyne (1999). The five items on role exchange and six items on collaboration were self-developed based on the previously described conceptual definitions of the variables. The process of scale development consisted of six major steps, as well described by (Gehlbach and Brinkworth 2011). These steps were as follows: literature review, interviews with focus groups, synthesizing the literature review with interview focus group data, developing items, expert validation, and finally pilot testing of our scales.

Decision satisfaction was measured with one item developed for this study: "I am satisfied with the way my partner and me make decisions".

Prior to the data collection, all scales were subject to a face validity check and an empirical pre-test on a sample of 25 individuals who fulfilled the requirements for the target respondents. The purpose was to ensure the survey and its questions were easy to navigate and the instructions easy to follow.

The multi-item scales were subject to a validation procedure where convergent validity was tested with a confirmatory factor analysis, followed by a Cronbach's alpha reliability test, using IBM SPSS Statistics 26. In order to examine the latent structure of the test instruments in the process of scale validation, confirmatory factor analysis (CFA) was used. CFA verified the number of factors and the pattern of item-factor relationships (Brown and Moore 2012). 
In order to provide the measure of internal consistency of our scales, that is the extent to which all items in the scale measure the same construct and are inter-related, the coefficient Cronbach alpha was calculated. Cronbach alpha number is between 0 and 1 , with most commonly acceptable values of alpha, ranging from 0.70 to 0.95 (Tavakol and Dennick 2011). Items with low factor loadings or impeding unidimensional factor structures were removed at this point in the process. Shared experiences received a unidimensional solution with factor scores between 0.93 and 0.72 . Cronbach alpha was estimated to 0.92 . The factor analysis on the five items capturing flexibility returned factor loadings ranging from 0.77 to 0.62 , with a Cronbach alpha value of 0.80 . The engagement scale gave us unidimensional solution, with factor scores from 0.84 to 0.52 and a Cronbach alpha of 0.85 . When testing the items for role exchange, two items were removed due to low factor scores or cross loadings. The three remaining items loaded on one single factor, with values between 0.99 and 0.40 . Cronbach alpha was 0.69 . The four items on partner support all loaded on the same factor, received factor scores from 0.77 to 0.52 and a Cronbach alpha value of 0.73 . Finally, the six items for collaboration returned a two-factor solution where one item was removed due to high cross loadings. A second item was then removed due to low factor scores, and the four remaining items gave us unidimensional solution with scores ranging from 0.72 to 0.62 , and a Cronbach alpha of 0.76 . Factor scores are presented in Table 1.

Table 1. Items, factor scores, and reliability for all variables.

\begin{tabular}{|c|c|c|c|}
\hline Scale & Item & Item Text & Factor Scores \\
\hline \multirow[t]{5}{*}{ Shared experiences } & Exp4 & $\begin{array}{l}\text { The experience we got from previous decisions was highly educative to us as } \\
\text { a couple }\end{array}$ & 0.93 \\
\hline & Exp3 & Previous decisions made together has been a real learning experience & 0.88 \\
\hline & Exp2 & We have learned a lot from making complex decisions together in the past & 0.85 \\
\hline & Exp5 & The experience we gained really enhanced our skills in decision-making & 0.84 \\
\hline & Exp1 & $\begin{array}{l}\text { The experiences we have together from earlier choice situations have made us } \\
\text { more knowledgeable }\end{array}$ & 0.72 \\
\hline \multirow[t]{5}{*}{ Flexibility } & Flex1 & My partner can find solutions to seemingly unsolvable decisions & 0.77 \\
\hline & Flex5 & $\begin{array}{c}\text { My partner has self-confidence necessary to try different ways of approaching } \\
\text { a decision }\end{array}$ & 0.73 \\
\hline & Flex3 & In any given choice situation, my partner is able to act appropriately & 0.63 \\
\hline & Flex4 & $\begin{array}{c}\text { My partner is willing to listen and consider alternatives when making a } \\
\text { decision }\end{array}$ & 0.62 \\
\hline & Flex2 & My partner is willing to work at creative solutions to decisions we make & 0.62 \\
\hline \multirow[t]{6}{*}{ Engagement } & Eng1 & I am enthusiastic in making decisions together with my partner & 0.84 \\
\hline & Eng2 & I feel energetic when making decisions together with my partner & 0.81 \\
\hline & Eng6 & When making decisions together, I am absorbed by our activity & 0.71 \\
\hline & Eng5 & $\begin{array}{c}\text { When making decisions together, I focus a great deal of my attention on } \\
\text { the process }\end{array}$ & 0.70 \\
\hline & Eng3 & I feel positive about making decisions together & 0.60 \\
\hline & Eng4 & $\begin{array}{l}\text { When we make decisions together, my mind is very focused on what I } \\
\text { am doing }\end{array}$ & 0.52 \\
\hline \multirow[t]{5}{*}{ Role exchange } & Exch1 & $\begin{array}{l}\text { Even though we might discuss alternatives, it is always my partner who } \\
\text { makes the final decision (r) }\end{array}$ & 0.99 \\
\hline & Exch5 & Before we make a final decision, it is always my partner who must approve it & 0.64 \\
\hline & Exch2 & $\begin{array}{l}\text { When we make decisions together, it is always my partner who seeks out } \\
\text { information on what alternatives there are to choose from (r) }\end{array}$ & 0.40 \\
\hline & Exch1 & $\begin{array}{l}\text { When making complex decisions together, who of us that take the initiative } \\
\text { will change from situation to situation (D) }\end{array}$ & \\
\hline & Exch3 & $\begin{array}{l}\text { The task of asking critical questions to what we are doing in a } \\
\text { decision-making process falls on me, other times on my partner (D) }\end{array}$ & \\
\hline
\end{tabular}


Table 1. Cont.

\begin{tabular}{|c|c|c|c|}
\hline Scale & Item & Item Text & Factor Scores \\
\hline \multirow[t]{4}{*}{ Partner's support } & Sup2 & My partner, as a part of a team, cares about decisions we make & 0.77 \\
\hline & Sup3 & My partner always contributes to making the best choices & 0.67 \\
\hline & Sup4 & My partner seems to enjoy when we make decisions together & 0.67 \\
\hline & Sup1 & $\begin{array}{l}\text { My partner gives up activities he/she enjoys doing to discuss complex } \\
\text { decisions/choices we have to make }\end{array}$ & 0.52 \\
\hline \multirow[t]{6}{*}{ Collaboration } & Coll2 & Decisions, which me and my partner take, are fair for both of us & 0.72 \\
\hline & Coll5 & We listen to and consider other's opinions regarding decisions we make & 0.71 \\
\hline & Coll6 & My partner's decision approval is important to me & 0.64 \\
\hline & Coll4 & $\begin{array}{c}\text { My partner and me suggest alternative options to reach an agreement during } \\
\text { choice situations }\end{array}$ & 0.62 \\
\hline & Coll1 & $\begin{array}{l}\text { When making complex choices my partner and me aim for win-win } \\
\text { solutions (D) }\end{array}$ & \\
\hline & Coll3 & Me and my partner compromise to reach a decision (D) & \\
\hline
\end{tabular}

(D) denotes deleted items, (r) denotes reversed items.

The items were summarized into one index for each individual variable, and Pearson correlations between all independent variables were computed. Discriminant validity can be claimed if no single pair of variables is perfectly correlated within the range of random error, as described by Anderson and Gerbing (1988). In this case, the pair of independent variables most highly correlated was flexibility and partner's support, with a correlation coefficient of $0.58(p=0.01)$. However, neither this nor any of the other correlations were close to violating the discriminant validity of the measures. Correlations between all variables are reported in Table 2.

Table 2. Correlations between all variables in the model.

\begin{tabular}{|c|c|c|c|c|c|c|}
\hline Variable & Shared Experiences & Flexibility & Engagement & Role Exchange & Partner's Support & Collaboration \\
\hline Flexibility & $0.48 * *$ & & & & & \\
\hline Engagement & $0.35 * *$ & $0.50 * *$ & & & & \\
\hline Role exchange & $0.24 *$ & $0.31 * *$ & $0.22 *$ & & & \\
\hline Partner's support & $0.49^{* *}$ & $0.58 * *$ & $0.32 * *$ & 0.17 & & \\
\hline Collaboration & $0.58 * *$ & $0.67^{* *}$ & $0.52 * *$ & $0.27^{* *}$ & $0.57 * *$ & \\
\hline $\begin{array}{l}\text { Decision } \\
\text { satisfaction }\end{array}$ & $0.46^{* *}$ & $0.61 * *$ & $0.45^{* *}$ & $0.39 * *$ & $0.55 * *$ & $0.70 * *$ \\
\hline
\end{tabular}

** Correlation significant at the 0.01 level (2-tailed); ${ }^{*}$ Correlation significant at the 0.05 level (2-tailed).

\section{Results}

To test all five hypotheses, the dependent variable collaboration was regressed on the five independent variables in a multiple regression model. Linear regression results demonstrate that four of the five hypotheses are supported. There is a positive and significant relationship between shared experiences and collaboration, with a standardized coefficient of $0.258(t=3.393, p=0.001)$. Flexibility has a standardized coefficient of 0.336 $(t=3.809, p=0.000)$, while engagement has a standardized coefficient of $0.193(t=2.618$, $p=0.010$ ). However, role exchange is not found to significantly influence collaboration, as the t-value equals 0.469 and $p=0.640$. Finally, the effect of partner support is significant and positive, with a standardized beta equal to $0.187, \mathrm{t}=2.326$ and $p=0.022$.

The model explains 59.5 percent of the variance in collaboration $\left(R^{2}=0.595\right.$, Adj. $\left.\mathrm{R}^{2}=0.575\right)$ and is significant $(\mathrm{F}=30,010 ; p=0.000)$. To rule out potential collinearity problems, the variance inflation factor (VIF) for all independent variables in the regression equation was calculated. According to Belsley (1991) the VIF value should not exceed 10, and with values ranging from 1.13 for role exchange to 1.96 for flexibility, multicollinearity does not seem to be a problem. The results of the linear regression are presented in Table 3. 
Table 3. Linear regression results of conceptual model test with collaboration as a dependent variable.

\begin{tabular}{lccc}
\hline \multicolumn{1}{c}{ Variable } & St. Beta & t-Value & $p$-Value \\
\hline Shared experiences & 0.258 & 3.393 & 0.001 \\
Flexibility & 0.336 & 3.809 & 0.000 \\
Engagement & 0.193 & 2.618 & 0.010 \\
Role Exchange & 0.031 & 0.469 & 0.640 \\
Partner's support & 0.187 & 2.326 & 0.022 \\
\hline
\end{tabular}

$$
\mathrm{R}^{2}=0.595, \text { Adj. } \mathrm{R}^{2}=0.575 \text {. }
$$

Decision satisfaction was measured with one item developed for this study: "I am satisfied with the way my partner and me make decisions", and we regressed this on the collaboration index variable. The results show that collaboration is a significant driver of satisfaction, lending additional support to the model presented (St. beta 0.702, $p=0.000$, $\mathrm{R}^{2}$ adj 0.488 ). This implies that not only are four of the suggested antecedents to collaboration supported by the data, but the effect collaboration is assumed to have on satisfaction is also significant and positive. We thus argue that the hypotheses presented and empirically supported, gives a valid picture of what drives collaboration in couples, and how it facilitates a more satisfactory decision-making process. The results are visualized in Figure 2.

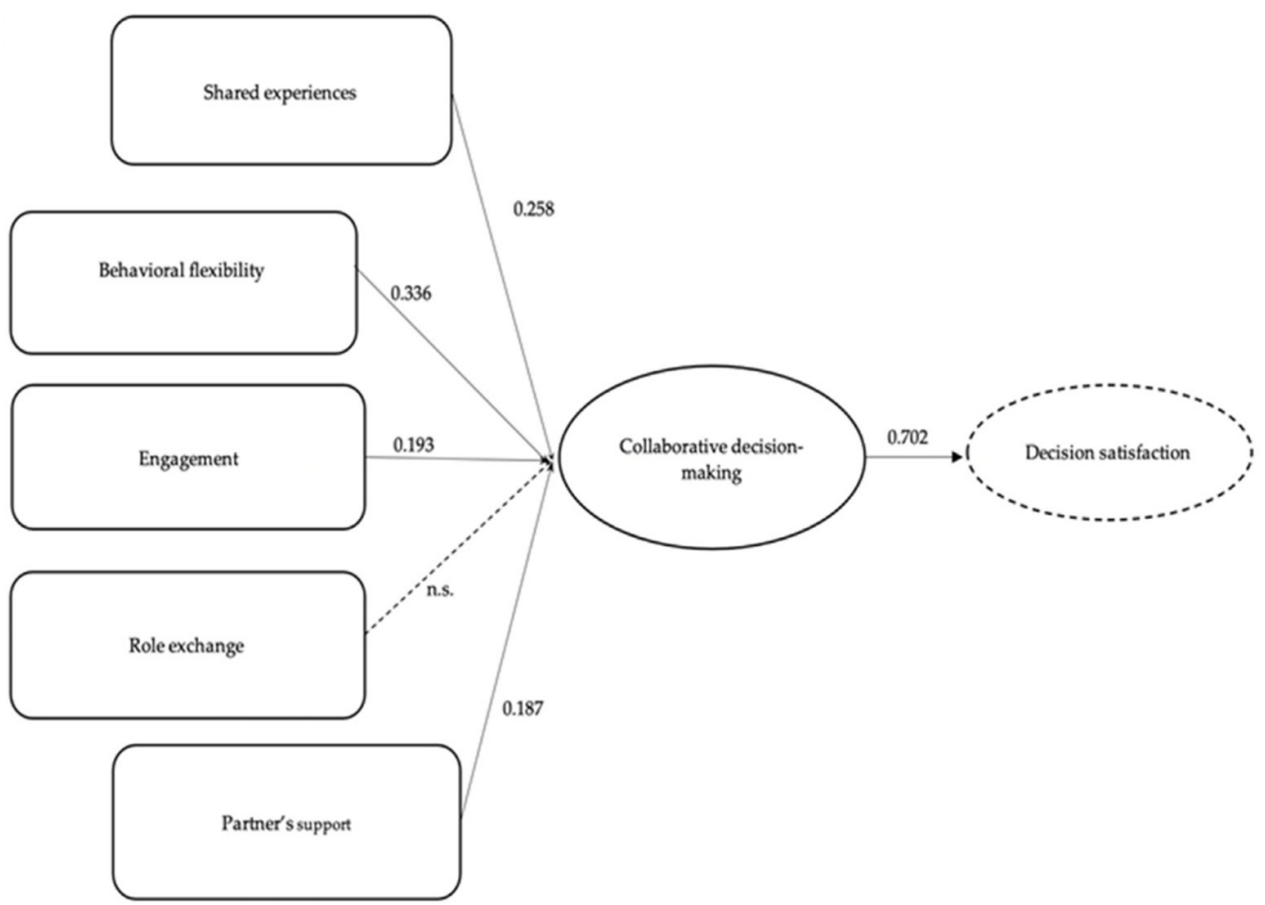

Figure 2. The conceptual model with empirical results included (St.beta).

\section{Discussion}

Supporting the suggested hypothesis, all but one factors positively affected the perception of decision-making collaboration. This means that when these attributes are present among partners, the perceptions of collaborative decision-making are more likely to flourish. The results of this study extend existing knowledge on collaborative decision-making in tourism couples in several ways. Firstly, when investigating how couples make decisions, most of the emphasis has been on gender roles and influence within a couple (Rojas-de Gracia and Alarcon-Urbistondo 2016; Simpson et al. 2012). This study extends this body of knowledge as it focuses on what drives collaborative decision-making, and how interpersonal characteristics may facilitate collaboration. When moving beyond more routinized choice situations, more extensive decision problems with higher levels of involvement and consequences, similar to those described in the introduction to this study, 
may follow other choice procedures. Secondly, our results are in line with the empirical and theoretical arguments in the field of collaboration. The study extends existing theory on collaborative decision-making by scrutinizing the role of shared experiences, flexibility, engagement, role exchange, and partner's support in the context of collaboration in tourism couples. Thirdly, the results demonstrate that flexibility $(\beta=0.336)$ and shared experiences ( $\beta=0.258)$ are the two strongest predictors among the four found to be significant. This is interesting, as these predictors are different in that flexibility encompasses interactional elements that portrays how couples adjust to each other during decision-making processes, while shared experiences encompass activity elements and relate to how previous choice processes has led to learning within the couple. Fourth, the importance of partner's support $(\beta=0.187)$ during collaborative decision-making may be explained by both partners feeling free to express their ideas, including those that may deviate from traditional ways of thinking (Wheeler and Janis 1980). This is also in line with the literature on spousal support (Khan et al. 2013).

Fifth, role exchange was not found to affect the perception of collaboration among partners. This was somewhat surprising, as roles have been found to be a key factor influencing the success of collaborative decision-making (Mattessich and Monsey 1992). While bordering to speculation, it might be that although important, role clarifications can be more central to decisions made by one of the partners (e.g., distribution of tasks) in larger groups, rather than to closer dyadic collaboration.

Finally, this research has demonstrated that during complex choice situations collaboration is a central driver of decision process satisfaction. This suggests that choice encounters, which have a collaborative nature, may be more engaging for both partners, turning decision-making into a more effective process. This can be explained by research on group processes, which postulates that greater participation in decision-making creates a greater sense of responsibility for the choice made, and thus results in decisions that are more accepted by all group members (Harrison 1999). Conversely, similar interactions characterized by one partner's use of influence was associated with lower decision satisfaction by the other partner (Su et al. 2003). The results reported here are in line with both these opposites.

For tourism, this research offers important insights into factors that affect collaboration in close relationships. For example, in their study of family holiday decision-making Rojas-de-Gracia et al. (2018) found that at least in the initiation phase and in the final decision couples practice a joint decision-making process. Our findings are in line with this study. This study supports the idea that couples are collective entities composed of two individuals, and that this large tourism segment should be understood in terms of couple properties rather than solely individual ones. This perspective also suggests that collaborative behavior in tourism couples should be understood independently from individual characteristics of its members, implying that groups have minds of their own (Harrison 1999). This holds important implications for the ways tourism marketers and operators address couples as a customer segment, and the ways they portray the "personas" in these segments. Firstly, tourism firms need to understand that when communicating services targeted towards couples, decision relevant information and decision systems should be designed to nurture collaborative decision-making. Secondly, describing the typical target customer in terms of personas is different when the purchasing unit is an individual and when it is a couple. Hence, tourism marketers should include couples in their persona definitions, and analyze how their target couples typically arrive at a decision. Further, for vacation-related decisions the path-to-purchase differs between couples and individuals, and tourism companies would benefit from acknowledging this in their marketing strategies. Thirdly, it could prove fruitful to remember that couples not only make collaborative decisions, but also consume the tourism product in collaboration. Drawing on this study, tourism companies could benefit from blueprinting their offers in line with the characteristics of couples as customers and draw on the connection between collaboration and satisfaction, also for the service experience itself. 
To summarize, the results of this study add to current theory by explaining how one of the largest purchasing units operates internally. If marketers gain an understanding of which factors influence collaboration in close relationships, they could facilitate collaborative processes in couples, perhaps through supporting technologies (Hara et al. 2003). This could prove to be a fruitful competitive advantage in the quest to attract one of the largest customer groups, and the one characterized by high economic purchasing power. As for couples, the knowledge and insight into their own decision-making processes may lead to more fruitful and satisfactory choices.

\section{Limitations, and Future Research}

Like all studies, this research has several limitations. Firstly, the data were collected only from Norwegian individuals in close relationships. Yet, there is a reason to believe that the way in which Norwegian consumer couples collaborate when making vacationsrelated decisions is similar to that of couples from other Western countries, as the concepts investigated are the baseline of human interaction in general. It should be specified that in cultures with other gender-based expectations and role definitions, the results may be less valid. More research on wider populations is therefore needed to generalize the model. Secondly, the theory on group dynamics cohesion or so-called forces that bind members of the group to each other may help to explain group behavior (Dion 2000) interpersonal consensus that satisfies its members and their joint interest. Thus, the relationships within the couple (e.g., degree of closeness between partners) may have shaped the results of this study. This means that in decision-making situation where cohesion among partners is low, collaboration may be influenced by still other factors (Dion 2000). Future studies may use Lewin's theory as a valuable tool for analyzing decision-making collaboration in different types of close relationships. For future research, it would be of interest to concentrate on consumer collaboration in close relationships by examining its other possible facilitators. Additionally, future research could concentrate on liabilities of consensual choices in couples, such as individual domination and acceptance of a "wrong" solution, as well as on situations with strict deadlocks due to the even number of group members (e.g., families with older children) (Harrison 1999), and on how couples maneuver in such situations. Most of the participants of our study were parents or grandparents of children. Consequently, children may be one of the factors affecting collaborative decision-making in these couples, having either a direct or a moderating effect. However, in order to keep to our research scope, we have not explored how decisions couples make may be influenced by their children. Culture, family situation, emotions, and moods are known to influence decision-making processes in couples (Decrop and Snelders 2005; Beresford and Sloper 2008) and could be further examined in relation to collaboration in a sample of individuals from and within different cultural and social settings. More research is needed in this area.

\section{Conclusions}

The factors tested to influence collaborative decision-making related to vacationing couples (individuals in close relationship) were based on existing theory in the area of collaborative and shared decision-making. To the best of our knowledge, this is the first study investigating how shared experiences, flexibility, engagement, role exchange, and partner's support affect the perception of collaborative decision-making in close relationships. Previous investigation of the above-mentioned factors in relation to collaboration was conducted in the context of more secondary types of groups. Consequently, these findings further indicate that there is more similarity among primary and secondary groups, validating for instance Hara et al. (2003).

Considering the circumstance that current knowledge on collaboration in couples is in its early stage (Queen et al. 2015), this study contributes to our still limited understanding of this phenomenon. Moreover, gaining a more profound understanding of decision-making approaches and strategies might be valuable to scientists from other research areas, such as engineers and technologists. The experiences from the COVID-19 global crisis have also 
demonstrated that our societies are less robust than was previously envisioned, and that alternative ways of problem solving may be needed on the level of couples.

Author Contributions: Conceptualization, writing original draft preparation, O.K.; methodology, validation, writing-review and editing, O.K. and H.H.; supervision, H.H. All authors have read and agreed to the published version of the manuscript.

Funding: This research received no external funding.

Institutional Review Board Statement: Not applicable.

Informed Consent Statement: Informed consent was obtained from all subjects involved in the study.

Data Availability Statement: The quantitative data will be shared upon request.

Conflicts of Interest: The authors declare no conflict of interest.

\section{References}

Abdullah, Muhammad, Charitha Dias, Deepti Muley, and Md Shahin. 2020. Exploring the impacts of COVID-19 on travel behavior and mode preferences. Transportation Research Interdisciplinary Perspectives 8: 100255. [CrossRef]

Anderson, James C., and David W. Gerbing. 1988. Structural equation modelling in practice: A review and recommended two-step approach. Psychological Bulletin 103: 411-23. [CrossRef]

Anderson, Carolyn M., Matthew M. Martin, and Dominic A. Infante. 1998. Decision-making collaboration scale: Tests of validity. Communication Research Reports 15: 245-55. [CrossRef]

Belsley, David A. 1991. A guide to using the collinearity diagnostics. Computer Science in Economics and Management 4: 33-50.

Beresford, Bryony, and Patricia Sloper. 2008. Understanding the Dynamics of Decision-Making and Choice: A Scoping Study of Key Psychological Theories to Inform the Design and Analysis of the Panel Study. York: Social Policy Research Unit, University of York.

Berg, Cynthia A., Vicki S. Helgeson, Eunjin Lee Tracy, Jonathan E. Butner, Caitlin S. Kelly, Meredith Van Vleet, and Michelle L. Litchman. 2020. Daily illness appraisal and collaboration in couples with type 1 diabetes. Health Psychology 39: 689-99. [CrossRef]

Berg, Cynthia A., Ines Schindler, Timothy W. Smith, Michelle Skinner, and Ryan M. Beveridge. 2011. Perceptions of the cognitive compensation and interpersonal enjoyment functions of collaboration among middle-aged and older married couples. Psychology and Aging 26: 167-73. [CrossRef] [PubMed]

Bronner, Fred, and Robert De Hoog. 2008. Agreement and disagreement in family vacation decision-making. Tourism Management 29: 967-79. [CrossRef]

Bronstein, Laura R. 2003. A model for interdisciplinary collaboration. Social Work 48: 297-306. [CrossRef]

Brown, Timothy A., and Michael T. Moore. 2012. Confirmatory factor analysis. In Handbook of Structural Equation Modeling. New York: The Guilford Press, pp. 361-79.

Christian, Michael S., Adela S. Garza, and Jerel E. Slaughter. 2011. Work engagement: A quantitative review and test of its relations with task and contextual performance. Personnel Psychology 64: 89-136. [CrossRef]

Couto, Gleiber, Luc Vandenberghe, and Wanessa Marques Tavares. 2018. Interpersonal interactions within couples: Convergences and divergences between self-description and partner's perception. Estudos de Psicologia (Campinas) 35: 309-19. [CrossRef]

Deci, Edward L., and Richard M. Ryan. 2000. The "What" and "Why" of Goal Pursuits: Human Needs and the Self-Determination of Behavior. Psychological Inquiry 11: 227-68. [CrossRef]

Decrop, Alain, and Dirk Snelders. 2005. A grounded typology of vacation decision-making. Tourism Management 26: 121-32. [CrossRef]

Dewey, John. 1938. Experience and Education. New York: Macmillan.

Dion, Kenneth L. 2000. Group cohesion: From "field of forces" to multidimensional construct. Group Dynamics: Theory, Research, and Practice 4: 7-26. [CrossRef]

Filiatrault, Pierre, and J. R. Brent Ritchie. 1980. Joint purchasing decisions: A comparison of influence structure in family and couple decision-making units. Journal of Consumer Research 7: 131-40. [CrossRef]

Fincham, Frank D. 2003. Marital conflict: Correlates, structure, and context. Current Directions in Psychological Science 12: 23-27. [CrossRef]

Garbinsky, Emily N., and Joe J. Gladstone. 2019. The Consumption Consequences of Couples Pooling Finances. Journal of Consumer Psychology 29: 353-69. [CrossRef]

Gehlbach, Hunter, and Maureen E. Brinkworth. 2011. Measure twice, cut down error: A process for enhancing the validity of survey scales. Review of General Psychology 15: 380-87. [CrossRef]

Gouldner, Alvin W. 1960. The norm of reciprocity: A preliminary statement. American Sociological Review 25: 161-78. [CrossRef]

Greenberger, Ellen, and Wendy A. Goldberg. 1989. Work, parenting, and the socialization of children. Developmental Psychology 25: 22-35. [CrossRef]

Gössling, Stefan, Daniel Scott, and Colin Hall. 2020. Pandemics, tourism and global change: A rapid assessment of COVID-19. Journal of Sustainable Tourism 29: 1-20. [CrossRef] 
Hall, Rosalie J., Judd W. Workman, and Christopher A. Marchioro. 1998. Sex, task, and behavioral flexibility effects on leadership perceptions. Organizational Behavior and Human Decision Processes 74: 1-32. [CrossRef]

Hara, Noriko, Paul Solomon, Seung-Lye Kim, and Diane H. Sonnenwald. 2003. An emerging view of scientific collaboration: Scientists' perspectives on collaboration and factors that impact collaboration. Journal of the American Society for Information science and Technology 54: 952-65. [CrossRef]

Harrison, E. Frank. 1999. The Managerial Decision-Making Process. Boston: Houghton Mifflin College Division.

Hilton, B. Ann, John A. Crawford, and Michel A. Tarko. 2000. Men's perspectives on individual and family coping with their wives' breast cancer and chemotherapy. Western Journal of Nursing Research 22: 438-59.

Kanter, Rosabeth Moss. 1994. Collaborative advantage. Harvard Business Review 72: 96-108.

Kapucu, Naim, and Vener Garayev. 2011. Collaborative decision-making in emergency and disaster management. International Journal of Public Administration 34: 366-75. [CrossRef]

Khan, Cynthia M., Mary Ann Parris Stephens, Melissa M. Franks, Karen S. Rook, and James K. Salem. 2013. Influences of spousal support and control on diabetes management through physical activity. Health Psychology 32: 739-47. [CrossRef] [PubMed]

Korsgaard, M. Audrey, David M. Schweiger, and Harry J. Sapienza. 1995. Building commitment, attachment, and trust in strategic decision-making teams: The role of procedural justice. Academy of Management Journal 38: 60-84.

Kotler, Philip, and Kevin Keller. 2011. Marketing Management. Hoboken: Pearson Prentice Hall.

Koval, Olena, and Håvard Hansen. 2019. Working it out together: A suggested model for vacation-related decision-making in couples. Scandinavian Journal of Hospitality and Tourism 19: 354-70. [CrossRef]

Kroesen, Maarten, and Susan Handy. 2014. The influence of holiday-taking on affect and contentment. Annals of Tourism Research 45: 89-101. [CrossRef]

Kuhn, Deanna, Victoria Shaw, and Mark Felton. 1997. Effects of dyadic interaction on argumentive reasoning. Cognition and Instruction 15: 287-315. [CrossRef]

Lobel, Sharon Alisa. 1991. Allocation of investment in work and family roles: Alternative theories and implications for research. Academy of Management Review 16: 507-21. [CrossRef]

Macey, William H., and Benjamin Schneider. 2008. The meaning of employee engagement. Industrial and Organizational Psychology 1: 3-30. [CrossRef]

Martin, Matthew M., and Rebecca B. Rubin. 1995. A New Measure of Cognitive Flexibility. Psychological Reports 76: 623-26. [CrossRef]

Mattessich, Paul W., and Barbara R. Monsey. 1992. Collaboration: What Makes It Work. A Review of Research Literature on Factors Influencing Successful Collaboration. St. Paul: ERIC.

Meyer, John P., and Marylene Gagne. 2008. Employee engagement from a self-determination theory perspective. Industrial and Organizational Psychology 1: 60-62. [CrossRef]

Moen, Phyllis, Qinlei Huang, Vandana Plassmann, and Emma Dentinger. 2006. Deciding the future: Do dual-earner couples plan together for retirement? American Behavioral Scientist 49: 1422-43. [CrossRef]

Nan Restine, L. 1997. Experience, meaning and principal development. Journal of Educational Administration 35: 253-67. [CrossRef]

Oh, Haemoon, Ann Marie Fiore, and Miyoung Jeoung. 2007. Measuring experience economy concepts: Tourism applications. Journal of Travel Research 46: 119-32. [CrossRef]

Peter-Wight, Melanie, and Mike Martin. 2010. When 2 is better than $1+1$. European Psychologist 16: 288-94. [CrossRef]

Politi, Mary C., and Richard L. Street. 2011. The importance of communication in collaborative decision making: Facilitating shared mind and the management of uncertainty. Journal of Evaluation in Clinical Practice 17: 579-84. [CrossRef]

Queen, Tara L., Cynthia A. Berg, and William Lowrance. 2015. A framework for decision making in couples across adulthood. In Aging and Decision Making: Empirical and Applied Pespectives. Edited by Strough Hess and öckenhoff. London: Elsevier.

Razzouk, Nabil, Victoria Seitz, and Karen Prodigalidad Capo. 2007. A comparison of consumer decision-making behavior of married and cohabiting couples. Journal of Consumer Marketing 24: 264-74. [CrossRef]

Richey, R. Glenn, Frank G. Adams, and Vivek Dalela. 2012. Technology and flexibility: Enablers of collaboration and time-based logistics quality. Journal of Business Logistics 33: 34-49. [CrossRef]

Rojas-de-Gracia, María-Mercedes, Pilar Alarcón-Urbistondo, and Ana-María Casado-Molina. 2019. Is asking only one member of a couple sufficient to determine who influences tourism decisions? Journal of Destination Marketing E Management 12: 55-63.

Rojas-de-Gracia, María-Mercedes, Pilar Alarcón-Urbistondo, and Eva María González Robles. 2018. Couple dynamics in family holidays decision-making process. International Journal of Contemporary Hospitality Management 30: 601-17. [CrossRef]

Rojas-de Gracia, María Mercedes, and Pilar Alarcon-Urbistondo. 2016. Toward a gender understanding of the influence of the couple on family vacation decisions. Tourism Management Perspectives 20: 290-98. [CrossRef]

Sharfman, Mark P., and James W. Dean Jr. 1997. Flexibility in strategic decision making: Informational and ideological perspectives. Journal of Management Studies 34: 191-217. [CrossRef]

Simpson, Jeffry A., Vladas Griskevicius, and Alexander J. Rothman. 2012. Consumer decisions in relationships. Journal of Consumer Psychology 22: 304-14. [CrossRef]

Solem, Birgit Andrine Apenes. 2015. The Process of Customer Brand Engagement in Interactive Contexts: Prerequisites, Conceptual Foundations, Antecedents, and Outcomes. Ph.D. dissertation, The Norwegian School of Economics and Business Administration, Bergen, Norway. 
Statista. 2021. Impact of Coronavirus (COVID-19) on Vacation Plans in the UK March 2020. Statista Research Department. Available online: https://www.statista.com/statistics/1105660/covid-19-impact-on-vacation-plans-in-the-uk/ \#statisticContainer (accessed on 30 March 2021).

Su, Chenting, Edward F. Fern, and Keying Ye. 2003. A Temporal Dynamic Model of Spousal Family Purchase-Decision Behavior. Journal of Marketing Research 40: 268-81. [CrossRef]

Saavedra, Richard, and Linn Van Dyne. 1999. Social exchange and emotional investment in work groups. Motivation and Emotion 23: 105-23. [CrossRef]

Tavakol, Mohsen, and Reg Dennick. 2011. Making sense of Cronbach's alpha. International Journal of Medical Education 2: 53. [CrossRef]

UNWTO. 2021. International tourism and COVID-19. Available online: https://www.unwto.org/international-tourism-and-covid-19 (accessed on 25 March 2021).

Webster, Cynthia, and Michelle C. Reiss. 2001. Do established antecedents of purchase decision-making power apply to contemporary couples? Psychology \& Marketing 18: 951-72.

Wheeler, Daniel D., and Irving Lester Janis. 1980. A Practical Guide for Making Decisions. New York: Free Press.

Witteman, Hal. 1988. Interpersonal problem solving: Problem conceptualization and communication use. Communications Monographs 55: 336-59. [CrossRef]

Zaccaro, Stephen J., Janelle A. Gilbert, Kirk K. Thor, and Michael D. Mumford. 1991. Leadership and social intelligence: Linking social perspectiveness and behavioral flexibility to leader effectiveness. The Leadership Quarterly 2: 317-42. [CrossRef] 